\title{
CORRECTION
}

View Article Online

View Journal | View Issue

Check for updates

Cite this: J. Mater. Chem. A, 2021, 9 17553

DOI: 10.1039/d1ta90162a

rsc.li/materials-a

\section{Correction: Recent advancements in solid electrolytes integrated into all-solid-state 2D and 3D lithium-ion microbatteries}

\author{
Albina Jetybayeva, ab Berik Uzakbaiuly, ${ }^{\text {abc }}$ Aliya Mukanova, ${ }^{\text {*abc }}$ Seung-Taek Myung ${ }^{d}$ \\ and Zhumabay Bakenov ${ }^{\star a b c}$ \\ Correction for 'Recent advancements in solid electrolytes integrated into all-solid-state 2D and 3D lithium- \\ ion microbatteries' by Albina Jetybayeva et al., J. Mater. Chem. A, 2021, 9, 15140-15178, DOI: 10.1039/ \\ D1TA02652F.
}

The authors regret that the funding information was incorrectly shown in the Acknowledgements section of the original manuscript. The corrected funding Acknowledgement is as shown below.

This work was supported by a research grant AP08052231 "Development of solid-state electrolytes with high ionic conductivity for the next generation of lithium-ion batteries" from the Ministry of Education and Science of the Republic of Kazakhstan and a research project no. 110119FD4504 "Development of 3D solid state thin film materials for durable and safe Li-ion microbatteries" from Nazarbayev University.

The Royal Society of Chemistry apologises for these errors and any consequent inconvenience to authors and readers. 